\title{
Choosing wisely in Allergology: a Slow Medicine approach to the discipline promoted by the Italian Society of Allergy, Asthma and Clinical Immunology (SIAAIC)
}

Enrico Heffler ${ }^{1 *}$, Massimo Landi ${ }^{2}$, Silvana Quadrino ${ }^{3,6}$, Cristoforo Incorvaia $^{4}$, Stefano Pizzimenti ${ }^{5}$, Sandra Vernero ${ }^{6}$, Nunzio Crimi ${ }^{1}$, Giovanni Rolla ${ }^{7}$ and Giorgio Walter Canonica ${ }^{8}$

\begin{abstract}
Background: One of the main problem health care systems are facis is the mis-use and over-use of medical resources (including useless exams, surgical interventions, medical treatments, screening procedures...) which may lead to high health care related costs without increased patients' benefit and possible harm to the patients themselves. The "Choosing wisely" campaign, in Italy denominated "Doing more does not mean doing better", tries to educate doctors and citizens at a correct use of medical resources.

Methods: the Italian Society of Allergy, Asthma and Clinical Immunology (SIAAIC) adhered to the "Doing more does not mean doing better" campaing and made a list of the 5 allergological procedures with the highest evidence of inappropriateness.

Results: the 5 recommendations were: "Do not perform allergy tests for drugs (including anhestetics) and/or foods when there are neither clinical history nor symptoms suggestive of hypersensitivity reactions"; "Do not perform the so-called "food intolerance tests" (apart from those which are validated for suspect celiac disease or lactose enzymatic intolerance)"; "Do not perform serological allergy tests (i.e.: total IgE, specific lgE, ISAC) as first-line tests or as "screening" assays"; "Do not treat patients sensitized to allergens or aptens if there is not a clear correlation between exposure to that specific allergen/apten and symptoms suggestive of allergic reaction"; "Do not diagnose asthma without having performed lung function tests".

Conclusions: An important role scientific societies should play is to advise on correct diagnostic and therapeutical pathways. For this reason SIAAIC decided to adhere to the Slow Medicine Italy campaign "Doing more does not mean doing better" with the aim of warning the scientific community and the citizens/patients about some allergological procedures, which, when performed in the wrong clinical setting, may be not only useless, but unnecessarily expensive and even harmful for patients' health.
\end{abstract}

Keywords: Allergy, Slow medicine, Chossing wisely, Appropriateness, Asthma, Food allergy

\section{Background}

The concept of "Slow Medicine" has been coined by Dr. Alberto Dolara, an Italian cardiologist that in 2002 invited his colleagues to give the deserved value to the

\footnotetext{
${ }^{*}$ Correspondence: heffler.enrico@gmail.com

${ }^{1}$ Department of Clinical and Experimental Medicine, Respiratory

Medicine and Allergy, University of Catania, Catania, Italy

Full list of author information is available at the end of the article
}

time spent in improving the patient-doctor relationship, implementing a more "human and thoughtful medicine" [1], but these underlying ideas were somehow anticipated from some phylosophers such as Ivan Illich that, with his "Medical nemesis" published in 1974, argued that the medicalization in recent decades of so many of life's vicissitudes-including birth and death-and the so called "hubris of medicine" frequently caused more harm than 
good and rendered many people in effect lifelong patients [2].

In the last few years, we assisted to a worldwide dramatic increase in interest in the "Slow Medicine" concept, and this was also endorsed by the former British Medical Journal (BMJ) editor in chief, professor Richard Smith, which wrote: "slow medicine-like slow food and slow lovemaking-is the best kind of medicine for the 21st century" [3].

One of the main problem the "Slow Medicine" approach is trying to face to promote possible solutions, is the mis-use and over-use of medical resources (including useless exams, surgical interventions, medical treatments, screening procedures...) which is well known to lead to both high health care related costs without increased patients' benefit [4] and possible harm to the patients themselves $[5,6]$.

Into this context, the "Choosing wisely" campaign started in the USA in $2012[7,8]$ and then spread in several other countries, including Italy with the name "Doing more does not mean doing better" ("Fare di più non significa fare meglio" in Italian) [9-11], has the main goal of identifying the most probable inappropriate medical procedures for each specialty, protecting patients' interests through a partnership between health professionals and patients and users [12].

In order to create an accurate list of the five medical procedures with the highest probability of inappropriateness for each specialty, Slow Medicine Italy [13] invited the most relevant Italian scientific societies to adhere to the "Doing more does not mean doing better" campaign. The Italian Society of Allergy, Asthma and Clinical Immunology (SIAAIC), the largest Italian scientific society in the field with more than 700 active members, enthusiastically adhered to the campaign. In this article we will described and discuss the methodology used and the obtained results to make the list of five allergological procedures with the highest probability of inappropriateness.

\section{Methods}

After formal adhesion of SIAAIC to the "Doing more does not mean doing better" campaign, a working group of senior and junior members of the Society and experts in the field of Allergology has been established. The board discussed and identified a first list of allergological procedures with a possible high degree of inappropriateness. The board members performed an extensive search on PubMed and Cochrane Database, without any limit of age, gender or time of publication, in order to find enough evidence of inappropriateness for each identified allergological procedure (search keywords were depending on the subjects of the identified allergologica procedures; all types of articles were included into the evaluation), selecting the five with the highest evidence of inappropriateness taking also in consideration the frequency and the social impact of each of them, and reporting them as a "do not" suggestion. The list of the identified 5 most inappropriate allergological procedures is reported in Table 1.

This list has been approved by both the Executive Committees of SIAAIC and Slow Medicine Italy, published on their websites $[14,15]$ and spread as a poster sent to all SIAAIC members.

\section{Results and discussion}

We here briefly discuss each of the identified 5 most inappropriate allergological procedures.

\section{Do not perform allergy tests for drugs (including anhestetics) And/or foods when there are neither clinical history nor symptoms suggestive of hypersensitivity reactions}

In absence of clinical history or symptoms suggestive of hypersensitivity reactions (i.e.: urticaria, angioedema, other typical muco-cutaneous manifestations, hypotension, respiratory symptoms, contemporary involvement of two or more organs, or any other consisting organ damage) allergometric tests do not have any clinical value and have a poor predictive value of future allergic reactions [16]. In this context, a positive allergometric test indicates only an immunological sensitization to the tested antigen.

\section{Table 1 The list of identified 5 most inappropriate allergological procedures}

\footnotetext{
Do not perform allergy tests for drugs (including anhestetics) and/or foods when there are neither clinical history nor symptoms suggestive of hypersensitivity reactions

Do not perform the so-called "food intolerance tests" (apart from those which are validated for suspect celiac disease or lactose enzymatic intolerance)

Do not perform serological allergy tests (i.e.: total lgE, specific lgE, component-resolved diagnosis) as first-line tests or as "screening" of inhalant \& food immediate hypersensitivity assays

Do not treat patients sensitized to allergens or aptens if there is not a clear correlation between exposure to that specific allergen/apten and symptoms suggestive of allergic reaction. This recommendation is particularly strong for allergen immunotherapy and elimination diets 
On the other hand, a negative test is indicative only of the current absence of sensitization but it does not exclude the possibility of future allergic reactions.

The harms connected to this procedure are:

1. Non adequate therapeutical approaches (including diets [16]) which are potentially harmful because they may preclude the use of drugs or the assumption of foods the patient is not allergic to;

2. it has been described, in two small non randomized controlled trials and therefore with low quality of evidence, the possibility of new sensitizations to the tested antigens induced by the tests themselves [17, $18]$.

\section{Do not perform the so-called "food intolerance tests" (apart from those which are validated for suspect celiac disease and lactose enzymatic intolerance)}

Several assays and techniques are constantly proposed to many patients to identify supposed food intolerance. These methods include, for example, VEGA-test, Cytotoxic test, serum specific IgG4 dosage, chemical analysis of hair, applied kinesiology, iridology, and "bioresonance" analysis. None of these methods reached sufficient evidence of efficacy, accuracy and repeatability in diagnosis food allergy/intolerance [19-28].

The use of these methods, giving unreliable and not clinically relevant results, put the patient at risk of inappropriate diets which are potentially harmful for health, without finding a solution to the symptoms reported by the patient $[29,30]$.

This recommendation is particularly important in a context of non adequate perception and knowledge of food allergy/intolerance symptoms by both patients and general practitioners [31].

Do not perform serological allergy tests (i.e.: total ige, specific ige, component-resolved diagnosis) as first-line tests or as "screening" of inhalant and food immediate hypersensitivity assays

Cutaneous allergometric tests, if possible, should be considered as the first diagnostic tests in case of consisting clinical history and symptoms with a suspect allergic reaction, as they give faster results, they are less invasive and cheaper than serological tests. Moreover, there is a moderate evidence that, at least for food allergies, that skin tests have at least the same diagnostic accuracy of serological tests $[32,33]$.

Exceptions to this recommendations are:

1. Situations in which cutaneous tests are not feasible, such as hypo- or hyper-reactive cutaneous states (i.e.: chronic assumption of antihistamines or systemic corticosteroids, or the presence of frank dermographism);

2. Non availability of any accurate extracts to perform skin tests against the availability of serological tests for the same allergen [16, 34].

3. When the clinical history suggests an unusually greater risk of anaphylaxis from skin testing [35].

Total IgE assessment is of limited clinical utility in most of the cases, as it is not necessarily indicative of allergic sensitization: allergic patients may have both normal or elevated total IgE levels, and patients with high total IgE levels are not necessarily atopic subjects $[16,34,36]$.

Measuring total IgE is otherwise indicated for the diagnosis of allergic bronchopulmonary aspergillosis, hyper IgE syndrome, as well for verification that the patient with severe allergic asthma is a suitable candidate for anti-IgE therapy with total serum IgE levels between 30 and $1500 \mathrm{IU} / \mathrm{ml}$.

Moreover, all serum allergological tests should be interpreted by specialists/experts in Allergy and Clinical Immunology as a wrong interpretation can lead a non expert doctor to offer therapeutical and/or dietetical inappropriate approaches which may be harmful for the patient's health.

\section{Do not treat patients sensitized to allergens or aptens} if there is not a clear correlation between exposure to that specific allergen/apten and symptoms suggestive of allergic reaction. This recommendation is particularly strong for allergen immunotherapy and elimination diets The finding of a positive allergometric test for an allergen or apten whose exposure is not associated with symptoms compatible with allergic reaction is only indicative of immunological sensitization and not necessarily of clinical manifestations related to hypersensitivity reaction $[16,34]$. Therefore, there is no indication to treat these patients.

Moreover, as far as food allergy, given the limitation of cutaneous and serological tests, oral food challenges (ideally Double-Blind Placebo-Controlled Food-Challenges) are still the gold standard in IgE and non IgE mediated food allergy in order to establish a firm diagnosis, determine threshold reactivity, assess tolerance and the response to immuno-modulation [37].

Suggesting a treatment (including immunotherapic or dietetic strategies) to these patients may expose them to the risk of useless and potentially harmful therapies [38-40].

In particular, elimination diets, when they are not indicated, may expose the patient to nutritional deficiencies with no improvement of symptoms for which the allergometric investigations had been carried out $[39,40]$. 


\section{Do not diagnose asthma without having performed lung function tests (including bronchodilating test and/or bronchial challenge)}

To rely only upon asthma-like symptoms (i.e.: dyspnea, chest tightness, cough, wheezing) is not sufficient to make a correct diagnosis of asthma, as these symptoms may be from alternate causes, such as chronic obstructive pulmonary disease (COPD), congestive heart failure, extrathoracic airway hyperresponsiveness syndromes (e.g. vocal cord dysfunction, VCD), gastroesophageal reflux disease, hyperventilation syndrome etc. [41-44]. This behavior can be harmful for patients as they may be receive a wrong treatment for their complaints; this is particularly important when patients are affected by other relevant comorbidities as it happens in elderly [45].

International asthma guidelines stress the need of performing complete lung function assessment to identify bronchial hyperreactivity and/or reversibility of bronchial obstruction [46]. Patients with asthma-like symptoms and normal spirometry should underwent to an aspecific bronchial challenge (i.e.: with methacholine) while those with an obstructive spirometric pattern should be evaluated for the degree of reversibility during a bronchodilating test (i.e.: with salbutamol). Beyond the increased costs of care, the consequences of misdiagnosing asthma include delaying a correct diagnosis and treatment [43].

\section{Conclusions}

In this article we described the methodology used and the obtained results to make the list of five allergological procedures with the highest probability of inappropriateness $[14,15]$, in the context of the "Doing more does not mean doing better" campaign proposed by Slow Medicine Italy [9-11]. The five selected procedures were identified by an expert panel of senior and junior Italian allergologists.

The modern medicine is imbued with inappropriate medical procedures, wastes, conflicts of interest and fraud deriving from the economic and financial interactions between prescribers, purchasers of health technologies and the industry [13]. Another important cause which may induce the doctors to order inappropriate procedures lies in malpractice claims from patients (defensive medicine). This behavior is often encouraged by the message, which comes from the "media" and easily received by patients, that in medicine "more is always better" and that "doing less is always an index of medical malpractice" [47].

An important role scientific societies should play is to produce and disseminate Diagnostic-TherapeuticHealthcare Protocols/Pathways, based on the best evidence based scientific knowledge, to guarantee the patients receive the correct diagnosis and the appropriate treatment. For this reason SIAAIC decided to adhere to the Slow Medicine Italy campaign "Doing more does not mean doing better" with the aim of warning the scientific community and the citizens/patients about some allergological procedures, which, when performed in the wrong clinical setting, may be not only useless, but unnecessarily expensive and even harmful for patients' health.

We think that doctors and patients should take more time to define together the most appropriate pathway which lead to the right diagnosis and to the most appropriate treatment. Doctors should always explain the patients what the exams they order mean in case they turned normal or altered and why some exams are not useful at all for the specific diagnosis the patients are looking for. An open and trustful patient-physician relationship appears to be important to avoid useless exams and to achieve more accurate diagnoses .

\section{Abbreviations \\ SIAAIC: Italian Society of Allergy, Asthma and Clinical Immunology; COPD: chronic obstructive pulmonary disease; VCD: vocal cord dysfunction.}

\section{Authors' contributions}

$\mathrm{EH}, \mathrm{SP}, \mathrm{Cl}, \mathrm{GR}, \mathrm{NC}, \mathrm{ML}$ and GWC were part of the SIAAIC experts board that defined the 5 procedures with high probability of inappropriateness, contributed in writing these procedures and this manuscript, and in critically revision the drafts of both the 5 selected procedures and the present article. SQ and SV gave their contribution supporting the SIAAIC working group with information on Slow Medicine and the "Choosing wisely" international project, writing part of the manuscript and critically revising it. All authors read and approved the final manuscript.

\section{Author details}

${ }^{1}$ Department of Clinical and Experimental Medicine, Respiratory Medicine and Allergy, University of Catania, Catania, Italy. ${ }^{2}$ Pediatrician Primary Care, Turin, Italy. ${ }^{3}$ "Change" Institute, Turin, Italy. ${ }^{4}$ Allergy/Pulmonary Rehabilitation, ICP Hospital, Milan, Italy. ${ }^{5}$ ASL-TO3, Allergy Outpatients' Clinic, "Edoardo Agnelli" Hospital, Pinerolo, TO, Italy. " "Slow Medicine Italy", Turin, Italy. ${ }^{7}$ Department of Medical Sciences, Allergy and Clinical Immunology, University of Torino, Turin, Italy. ${ }^{8}$ Allergy and Respiratory Diseases Clinic, DIMI-Department of Internal Medicine, IRCCS AOU S.Martino-IST, Genoa, Italy.

\section{Competing interests}

The authors declare that they have no competing interests.

Received: 29 July 2015 Accepted: 28 September 2015

Published online: 20 November 2015

\section{References}

1. Dolara A. Invitation to "slow medicine". Ital Heart J Suppl. 2002;3(1):100-1.

2. Illich I. Medical nemesis. London: Calder \& Boyars; 1974.

3. Smith R. The case for slow medicine. 2012. http://blogs.bmj.com/ bmj/2012/12/17/richardsmith-the-case-for-slow-medicine.

4. Himmelstein DU, Woolhandler S. Cost without benefit. Administrative waste in U.S. health care. N Engl J Med. 1986;314(7):441-5.

5. BMJ Evidence Center: Clinical evidence Handbook. BMJ Publishing Group. 2012. http://clinicalevidence.bmj.com/x/set/static/cms/ce-handbook.html. 
6. Krogsbøll LT, Jørgensen KJ, Larsen CG, Gøtzsche PC. General health checks in adults for reducing morbidity and mortality from disease: Cochrane systematic review and meta-analysis. BMJ. 2012;345:e7191.

7. http://www.choosingwisely.org/.

8. Levinson W, Kallewaard M, Bhatia RS, Wolfson D, Shortt S, Kerr EA, Choosing Wisely International Working Group Wisely International Working Group. 'Choosing Wisely': a growing international campaign. BMJ Qual Saf. 2015;24(2):167-74.

9. Vernero S. Choosing wisely and Italy's "Doing more does not mean doing better" project. Rev Allergy Clin Immunol. 2014;24:1-3.

10. Vernero S, Domenighetti G, Bonaldi A. Italy's "Doing more does not mean doing better" campaign. BMJ. 2014;349:94703.

11. http://www.slowmedicine.it/fare-di-piu-non-significa-fare-meglio/ pratiche-arischio-di-inappropriatezza-in-italia.html.

12. Hurley R. Can doctors reduce harmful medical overuse worldwide? BMJ. 2014;349:94289.

13. Bonaldi A, Vernero S. Italy's slow medicine: a new paradigm in medicine. Recenti Prog Med. 2015;106(2):85-91.

14. http://www.siaaic.eu/source-siaaic/Segreteria/Eventi/Slow_Medicine_ in\%20allergologia.pdf.

15. http://www.slowmedicine.it/pdf/Pratiche/Societ\%C3\%A0\%20ltaliana\%20 di\%20Allergologia,\%20Asma\%20e\%20Immunologia\%20Clinica\%20 (SIAAIC)-\%20allergologia.pdf.

16. Boyce JA, Assa'ad A, Burks AW, Jones SM, Sampson HA, Wood RA, Plaut M, Cooper SF, Fenton MJ, Arshad SH, Bahna SL, Beck LA, Byrd-Bredbenner C, Camargo CA Jr, Eichenfield L, Furuta GT, Hanifin JM, Jones C, Kraft M, Levy BD, Lieberman P, Luccioli S, McCall KM, Schneider LC, Simon RA, Simons FE, Teach SJ, Yawn BP, Schwaninger JM. Guidelines for the diagnosis and management of food allergy in the United States: report of the NIAIDsponsored expert panel. J Allergy Clin Immunol. 2010;126(6 Suppl):S1-58.

17. Nugent JS, Quinn JM, McGrath CM, Hrncir DE, Boleman WT, Freeman TM Determination of the incidence of sensitization after penicillin skin testing. Ann Allergy Asthma Immunol. 2003;90(4):398-403.

18. Uter W, Hillen U, Geier J. Is incident sensitization to p-phenylenediamine related to particular exposure patterns? Results of a questionnaire study. Contact Dermat. 2007;56(5):266.

19. Stapel SO, Asero R, Ballmer-Webwe BK. Testing for lgG4 against foods is not recommended as a diagnostic tool. EAACI Task Force Report. Allergy. 2008;63:793-6.

20. Carr S, Chan E, Lavine E, Moote W. CSACI Position statement on the testing of food-specific IgG. Allerg Asthma Clin Imunol. 2012;8(1):12.

21. Senna G, Bonadonna P, Schiappoli M, Leo G, Lombardi C, Passalacqua G. Pattern of use and diagnostic value of complementary/alternative tests for adverse reactions to food. Allergy. 2005;60(9):1216-7.

22. Semizzi M, Senna G, Crivellaro M, Rapacioli G, Passalacqua G, Canonica WG, Bellavite P. A double-blind, placebo-controlled study on the diagnostic accuracy of an electrodermal test in allergic subjects. Clin Exp Allergy. 2002;32(6):928-32.

23. Garron JS. Kinesiology and food allergy. Br Med J Clin Res Ed. 1988;296(6636):1573-4.

24. Lüdtke R, Kunz B, Seeber N, Ring J. Test-retest-reliability and validity of the Kinesiology muscle test. Complement Ther Med. 2001;9(3):141-5.

25. Ernst E. Iridology: not useful and potentially harmful. Arch Ophthalmol. 2000;118(1):120-1.

26. Barrett S. Commercial hair analysis. Science or scam? JAMA 1985;254(8):1041-5.

27. Sethi TJ, Lessof MH, Kemeny DM, Lambourn E, Tobin S, Bradley A. How reliable are commercial allergy tests? Lancet. 1987;1(8524):92-4.

28. Lewith GT, Kenyon JN, Broomfield J, Prescott P, Goddard J, Holgate ST. Is electrodermal testing as effective as skin prick tests for diagnosing allergies? A double blind, randomised block design study. BMJ. 2001;322(7279):131-4

29. Senna G, Gani F, Leo G, Schiappoli M. Alternative tests in the diagnosis of food allergies. Recenti Prog Med. 2002;93(5):327-34.

30. Senna G, Passalacqua G, Crivellaro M, Bonadonna P, Gani F, Dorizzi R, Dama A, Canonica GW, Lombardi C. Unconventional medicine: a risk of undertreatment of allergic patients. Allergy. 1999;54(10):1117-9.
31. Heffler E, Minciullo PL, Fassio F, Rossi FW, Patafi M, Mondino M, Badiu I, Guida G on the behalf of Junior Members working group of Italian Society of Allergy and Clinical Imunology (SIAIC). Pertinence of requested allergy consultations for suspected food allergy/intolerance. A Junior Members working group of Italian Society of Allergy and Clinical Immunology (SIAIC) multicenter study. Ital J Allergol Clin Immunol 2011;21:18-24

32. Chafen JJ, Newberry SJ, Riedl MA, Bravata DM, Maglione M, Suttorp MJ, Sundaram V, Paige NM, Towfigh A, Hulley BJ, Shekelle PG. Diagnosing and managing common food allergies: a systematic review. JAMA 2010;303(18):1848-56.

33. Schneider Chafen JJ, Newberry S, Riedl M, Bravata DM, Maglione M, Suttorp M, Sundaram V, Paige NM, Towfigh A, Hulley BJ, Shekelle PG. Prevalence, Natural History, Diagnosis, and Treatment of Food Allergy. A Systematic Review of the Evidence. RAND Corporation. 2010. http:// www.rand.org/content/dam/rand/pubs/working_papers/2010/RAND_ WR757-1.pdf.

34. Sicherer SH, Wood RA, American Academy of Pediatrics Section On Allergy And Immunology. Allergy testing in childhood: using allergenspecific lgE tests. Pediatrics. 2012;129(1):193-7.

35. Bernstein IL, Li JT, Bernstein DI, Hamilton R, Spector SL, Tan R, Sicherer S, Golden DB, Khan DA, Nicklas RA, Portnoy JM, Blessing-Moore J, Cox L, Lang DM, Oppenheimer J, Randolph CC, Schuller DE, Tilles SA, Wallace DV, Levetin E, Weber R, American Academy of Allergy, Asthma and Immunology, American College of Allergy, Asthma and Immunology. Allergy diagnostic testing: an updated practice parameter. Ann Allergy Asthma Immunol. 2008;100(3 Suppl 3):S1-148.

36. Kerkhof M, Dubois AE, Postma DS, Schouten JP, de Monchy JG. Role and interpretation of total serum IgE measurements in the diagnosis of allergic airway disease in adults. Allergy. 2003;58(9):905-11.

37. Muraro A, Werfel T, Hoffmann-Sommergruber K, Roberts G, Beyer K, Bindslev-Jensen C, Cardona V, Dubois A, duToit G, Eigenmann P, Fernandez Rivas M, Halken S, Hickstein L, Høst A, Knol E, Lack G, Marchisotto MJ, Niggemann B, Nwaru BI, Papadopoulos NG, Poulsen LK, Santos AF, Skypala I, Schoepfer A, Van Ree R, Venter C, Worm M, Vlieg-Boerstra B, Panesar S, de Silva D, Soares-Weiser K, Sheikh A, Ballmer-Weber BK, Nilsson C, de Jong NW, Akdis CA; EAACI Food Allergy and Anaphylaxis Guidelines Group. EAACI food allergy and anaphylaxis guidelines: diagnosis and management of food allergy. Allergy. 2014;69(8):1008-25.

38. Passalacqua G, Compalati E, Canonica GW. Sublingual Immunotherapy: clinical indications in the WAO-SLIT Position Paper. World Allergy Organ J. 2010;3(7):216-9.

39. NICE Diagnosis and assessment of food allergy in children and young people in primary care and community settings. 2011. http://guidance. nice.org.uk/CG116/Guidance.

40. Guidance on food allergy in children. Editorial. The Lancet. 2011;377:691.

41. Luks VP, Vandemheen KL, Aaron SD. Confirmation of asthma in an era of overdiagnosis. Eur Respir J. 2010;36:255-60.

42. Aaron SD, Vandemheen $\mathrm{KL}$, Boulet $\mathrm{LP}$, et al. Overdiagnosis of asthma in obese and nonobese adults. CMAJ. 2008;179:1121-31.

43. Heffler E, Pizzimenti S, Guida G, Bucca C, Rolla G. Prevalence of over-/ misdiagnosis of asthma in patients referred to an allergy clinic. J Asthma. 2015;19:1-4. doi: 10.3109/02770903.2015.1026442. (Epub ahead of print).

44. Goldstein MF, Veza BA, Dunsky EH, et al. Comparisons of peak diurnal expiratory flow variation, postbronchodilator FEV(1) responses, and methacholine inhalation challenges in the evaluation of suspected asthma. Chest. 2001;119:1001-10.

45. Scichilone N, Ventura MT, Bonini M, Braido F, Bucca C, Caminati M, Del Giacco S, Heffler E, Lombardi C, Matucci A, Milanese M, Paganelli R, Passalacqua G, Patella V, Ridolo E, Rolla G, Rossi O, Schiavino D, Senna G, Steinhilber G, Vultaggio A, Canonica G. Choosing wisely: practical considerations on treatment efficacy and safety of asthma in the elderly. Clin Mol Allergy. 2015;13(1):7.

46. Global Initiative for Asthma (GINA). Global strategy for asthma mangement and prevention. 2011. http://www.ginasthma.org.

47. Toraldo DM, Vergari U, Toraldo M. Medical malpractice, defensive medicine and role of the "media" in Italy. Multidiscip Respir Med. 2015;10(1):12. 